Available online at http://jurnal.stmikroyal.ac.id/index.php/jurteksi

\title{
SISTEM PENGAMBILAN KEPUTUSAN DALAM MENENTUKAN KUALITAS PEMASUKAN PANGAN SEGAR METODE SMART
}

\author{
Trinanda Syahputra ${ }^{1}$, Milva Yetri ${ }^{1}$, Siwi Dwi Armaya ${ }^{1}$ \\ ${ }^{1,2,3}$ Sistem Informasi, STMIK Triguna Dharma \\ email: trinandasyahputra@gmail.com
}

\begin{abstract}
Fresh food from plants is a food that is high risk to chemical contamination that can disturb human health so it needs to be tested its quality. Decision Support System is an interactive system that supports decisions in the process of decision making through the alternatives obtained from the data processing, information and model design. The Smart method is a multi-attribute decision-making method used to support the manufacturer in choosing between alternatives. Results on the determination of the quality of fresh food imports from plants.
\end{abstract}

Keywords: expert system, smart method, food

\begin{abstract}
Abstrak: Pangan segar asal tumbuhan merupakan pangan yang beresiko tinggi terhadap cemaran kimia yang dapat mengganggu kesehatan manusia sehingga perlu dilakukan uji kualitasnya. Sistem Pendukung Keputusan merupakan suatu sistem interaktif yang mendukung keputusan dalam proses pengambilan keputusan melalui alternatif-alternatif yang diperoleh dari hasil pengolahan data, informasi dan rancangan model. Metode Smart merupakan metode pengambilan keputusan multi atribut yang digunakan untuk mendukung pembuat dalam memilih antara beberapa alternatif. Hasil terhadap penentuan kualitas pemasukan pangan segar asal tumbuhan.
\end{abstract}

Kata kunci: sistem pakar, metode smart, pangan

\section{PENDAHULUAN}

Pangan Segar Asal Tumbuhan (PSAT) adalah pangan asal tumbuhan yang dihasilkan dari proses pasca panen untuk konsumsi maupun sebagai bahan baku. Pangan segar asal tumbuhan merupakan pangan yang beresiko tinggi terhadap cemaran kimia (residu pestisida, mikotoksin, logam berat) yang dapat mengganggu kesehatan manusia sehingga perlu dilakukan uji kualitasnya, dan dilakukan pengawasan di Negara asal maupun pada saat masuk ke wilayah Indonesia. Hal ini untuk menjamin bahwa pangan segar yang masuk tidak tercemar oleh cemaran kimia sehingga aman dan layak untuk dikonsumsi oleh manusia sehari-hari maupun dalam kurun waktu yang lama. Pangan segar asal tumbuhan memiliki beberapa alternatif seperti buah, sayur, sereal, kacang-kacangan dan tanaman perkebunan yang masuk ke Balai Karantina Pertanian Kelas II Medan untuk dilakukan pengujian atas kualitas pangan. Tetapi pada Balai Karantina Pertanian kelas II Medan sering terjadi beberapa kendala dalam menentukan kualitas pangan segar asal tumbuhan, adapun kendalanya adalah para petugas karantina 
Available online at http://jurnal.stmikroyal.ac.id/index.php/jurteksi

tumbuhan memerlukan waktu yang lama untuk melakukan pemeriksaan baik dokumen maupun pangan segar tersebut karena setiap pangan segar yang masuk harus melalui proses pemeriksaan dilaboraturium dan selanjutnya data hasil laboraturium akan diproses secara manual dibagian karantina tumbuhan dan proses itu akan memakan waktu 1 sampai 2 hari sehingga pihak instansi memerlukan adanya sebuah sistem pendukung keputusan.

Sistem Pendukung Keputusan merupakan suatu sistem interaktif yang mendukung keputusan dalam proses pengambilan keputusan melalui alternatifalternatif yang diperoleh dari hasil pengolahan data, informasi dan rancangan model. Dalam perancangan sistem pendukung keputusan dibutuhkan sebuah metode yang diterapkan dalam perhitungan dimana sistem pendukung keputusan ini menggunakan metode Smart.

Metode Smart (Simple Multi Attribute Rating Technique) merupakan metode pengambilan keputusan multi atribut yang digunakan untuk mendukung pembuat dalam memilih antara beberapa alternatif. Setiap pembuat keputusan harus memilih sebuah alternatif yang sesuai dengan tujuan yang telah dirumuskan. Setiap alternatif terdiri dari sekumpulan atribut dan setiap atribut mempunyai nilai-nilai. Nilai ini diratarata dengan skala tertentu.

Maka tujuan yang akan dicapai dari penelitian ini adalah:

1. Untuk menganalisa permasalahan yang terjadi berkenaan dengan kualitas pemasukan pangan segar asal tumbuhan.

2. Untuk merancang aplikasi yang mengadopsi metode Smart yang dapat digunakan untuk menentukan kualitas pemasukan pangan segar asal tumbuhan secara tapat dan akurat.

3. Untuk menguji sistem yang telah dibuat dan melihat sejauh mana kinerjanya didalam pemecahan per- masalahan berkaitan dengan penentuan kualitas pemasukan pangan segar asal tumbuhan.

4. Untuk menerapkan aplikasi yang dibuat dengan menggunakan metode Smart dalam menentukan kualitas pemasukan pangan segar asal tumbuhan.

\section{METODOLOGI}

SMART menggunakan linier additive model untuk meramal nilai dari setiap alternatif. SMART merupakan metode pengambilan keputusan yang fleksibel. SMART lebih banyak digunakan karena kesederhanaannya dalam merespon kebutuhan pembuat keputusan dan caranya menganalisa respon. Analisa yang terlibat adalah transparan sehingga metode ini memberikan pemahaman masalah tinggi dan dapat diterima oleh pembuat keputusan.

SMART lebih banyak digunakan karena kesederhanaannya dalam merespon kebutuhan pembuat keputusan dan caranya menganalisa respon. Analisa yang terlibat adalah transparan sehingga metode ini memberikan pemahaman masalah yang tinggi dan dapat diterima oleh pembuat keputusan. Pembobotan pada SMART menggunakan skala antara 0 sampai 1, sehingga mempermudah perhitungan dan perbandingan nilai pada masing-masing alternatif. SMART:

Model yang digunakan dalam

$$
U\left(a_{i}\right)=\sum_{j=1}^{m} W j U i(a i), i=1,2, \ldots m
$$

Keterangan:

$\mathrm{Wj}=$ nilai pembobotan kriteria ke-j dan $k$ kriteria

$\mathrm{U}(\mathrm{ai})=$ nilai utility kriteria ke- $i$ untuk kriteria ke- $i$

Teknik SMART

a) Langkah 1: menentukan jumlah kriteria

b) Langkah 2: sistem secara default memberikan skala $0-100$ 
Available online at http://jurnal.stmikroyal.ac.id/index.php/jurteksi

berdasarkan prioritas
yang telah diinputkan
kemudian dilakukan nor-
malisasi.

$$
\text { Normalisasi }=\frac{w j}{\sum w j}
$$

Keterangan:

$\mathrm{Wj}$ : bobot suatu kriteria

$\sum w j$ : total bobot semua kriteria

c) Langkah 3: memberikan nilai kriteria untuk setiap alternatif

d) Langkah 4: hitung nilai utility untuk setiap kriteria masingmasing

$$
U_{i}\left(a_{i}\right)=100 \frac{\left(C \max -C_{\text {out }}\right)}{(C \max -C \min )} \%
$$

Keterangan:

$U_{i}\left(a_{i}\right)=$ nilai utility kriteria ke-1 untuk kriteria ke-i

Cmax = nilai kriteria maksimal

Cmin = milai kriteria minimal

Couti $=$ nilai kriteria ke- 1

e) Langkah 5: hitung nilai akhir masingmasing.

$U_{i}\left(a_{i}\right)=\sum_{j=1}^{m} W_{j} U_{i}(a i)$,

(iii)

\section{HASIL DAN PEMBAHASAN}

Berdasarkan ketentuan perusahaan jika nilai akhir/hasil $<16$ maka nilai tersebut dikatakan berkualitas dan layak konsumsi tetapi jika nilai akhir/hasil > 16 maka nilai tersebut tidak berkualitas atau tidak layak konsumsi. Adapun algoritma dalam penyelesaian dari metode SMART (Simple Multi Attribute Rating Technique) yaitu sebagai berikut:

1. Menentukan jumlah kriteria

Menentukan jumlah kriteria dari keputusan yang akan di ambil untuk mendapatkan rating kecocokan alternatif pada setiap kriteria tersebut dengan keterangan nilai sebagai berikut:

Tabel 1. Tabel Kriteria

\begin{tabular}{clcc}
\hline No & \multicolumn{1}{c}{$\begin{array}{c}\text { Nama } \\
\text { Kriteria }\end{array}$} & Nilai & Ket \\
\hline 1 & $\begin{array}{l}\text { Lamanya hari } \\
\text { pasca panen } \\
\text { (K1) }\end{array}$ & $90-100$ & $\begin{array}{c}\text { Sangat } \\
\text { Baik }\end{array}$ \\
\hline 2 & $\begin{array}{l}\text { Kondisi Fisik } \\
\text { (K2) }\end{array}$ & $75-89$ & Baik \\
\hline 3 & Warna (K3) & $60-75$ & Sedang \\
\hline 4 & $\begin{array}{l}\text { Residu } \\
\text { Pestisida (K4) }\end{array}$ & $50-59$ & $\begin{array}{c}\text { Kurang } \\
\text { Baik }\end{array}$ \\
\hline
\end{tabular}

2. Memberikan nilai normalisasi bobot kriteria

Adapun nilai normalisasi bobot yang diberikan berdasarkan ketentuan instansi atau perusahaan adalah 0-100 $\left(\mathrm{Wj} / \sum W_{j}\right)$. Dari nilai bobot kriteria inilah yang nanti akan menjadi penentu hasil perkalian dengan nilai uji laboraturium.

Tabel 2. Tabel Normalisasi Bobot Kriteria

\begin{tabular}{lllc}
\hline No & $\begin{array}{c}\text { Nama } \\
\text { Kriteria }\end{array}$ & $\begin{array}{c}\text { Bobot } \\
(\mathbf{W j})\end{array}$ & Normalisasi \\
\hline & $\begin{array}{l}\text { Lamanya } \\
\text { hari pasca } \\
\text { panen } \\
(\mathrm{K} 1)\end{array}$ & $35 \%$ & 0.35 \\
\hline 2 & $\begin{array}{l}\text { Kondisi } \\
\text { Fisik (K2) }\end{array}$ & $30 \%$ & 0.30 \\
\hline 3 & $\begin{array}{l}\text { Warna } \\
(\text { K3) }\end{array}$ & $25 \%$ & 0.25 \\
\hline 4 & $\begin{array}{l}\text { Residu } \\
\text { Pestisida } \\
(\text { K4) }\end{array}$ & $10 \%$ & 0.1 \\
\hline
\end{tabular}

3. Membuat daftar nilai hasil uji laboraturium

Dari hasil analisa data yang dilakukan oleh peneliti, berikut ini adalah 
Available online at http://jurnal.stmikroyal.ac.id/index.php/jurteksi

Tabel 3. Hasil Uji Laboraturium

\begin{tabular}{llcccc}
\hline No & Alternatif & $\begin{array}{c}\text { K1 } \\
\text { (Lamanya Hari } \\
\text { Pasca Panen) }\end{array}$ & $\begin{array}{c}\text { K2 } \\
\text { (Kondisi } \\
\text { Fisik) }\end{array}$ & $\begin{array}{c}\text { K3 } \\
\text { (Warna) }\end{array}$ & $\begin{array}{c}\text { K4 } \\
\text { (Residu } \\
\text { Pestisida) }\end{array}$ \\
\hline 1 & Apel Anna & 80 & 90 & 85 & 85 \\
\hline 2 & Apel Fuji & 80 & 75 & 90 & 80 \\
\hline 3 & Apel Granny Smith & 85 & 80 & 85 & 70 \\
\hline \multicolumn{5}{r}{} & \multicolumn{2}{c}{ Sumber: Balai Karantia Pertanian Kelas II Medan }
\end{tabular}

data dari pemasukan buah yang termasuk dalam pangan segar asal tumbuhan yang lebih sering dikirim oleh pengguna jasa adalah Apel Anna, Apel Fuji, dan Apel Granny Smith dengan range penilaian yaitu antara $50-100$.

4. Menghitung nilai Utility untuk setiap kriteria masing-masing:

$$
U_{i}\left(a_{i}\right)=100 \frac{(\text { max }- \text { Cout } 1)}{(\text { max }-C \min )} \%
$$

Keterangan:

$U_{i}\left(a_{i}\right)=$ nilai utility kriteria ke-1 untuk kriteria ke-i

Cmax = nilai kriteria maksimal

$\mathrm{Cmin}=$ milai kriteria minimal

Cout i = nilai kriteria ke-1

Rancangan model untuk mengevaluasi penentuan kualitas buah yang termasuk dalam pangan segar asal tumbuhan, tabel nilai utility ini menghitung hasil dari uji lab yang menunjukkan tingkat baik atau buruk serta ada tidaknya kecacatan dari alternatif yang akan dikirim atau dikonsumsi. Tabel nilai utility adalah sebagi berikut:

Tabel 4. Nilai Utility Apel Anna (C1)

\begin{tabular}{cccc}
\hline No & Kriteria & $\begin{array}{c}\text { Hasil Uji } \\
\text { Labora- } \\
\text { turium }\end{array}$ & $\boldsymbol{U}_{\boldsymbol{i}}\left(\boldsymbol{a}_{\boldsymbol{i}}\right)$ \\
\hline 1 & $\mathrm{~K} 1$ & 80 & 20 \\
\hline 2 & $\mathrm{~K} 2$ & 90 & 10 \\
\hline 3 & $\mathrm{~K} 3$ & 85 & 15 \\
\hline 4 & $\mathrm{~K} 4$ & 85 & 15 \\
\hline
\end{tabular}

Tabel 5. Nilai Utility Apel Fuji (C2)

\begin{tabular}{cccc}
\hline No & Kriteria & $\begin{array}{c}\text { Hasil Uji } \\
\text { Labora- } \\
\text { turium }\end{array}$ & $\boldsymbol{U}_{\boldsymbol{i}}\left(\boldsymbol{a}_{\boldsymbol{i}}\right)$ \\
\hline 1 & $\mathrm{~K} 1$ & 80 & 20 \\
\hline 2 & $\mathrm{~K} 2$ & 75 & 25 \\
\hline 3 & $\mathrm{~K} 3$ & 90 & 10 \\
\hline 4 & $\mathrm{~K} 4$ & 80 & 20 \\
\hline
\end{tabular}

Tabel 6. Nilai Utility Apel Granny Smith (C3)

\begin{tabular}{cccc}
\hline No & Kriteria & $\begin{array}{c}\text { Hasil Uji } \\
\text { Labora- } \\
\text { turium }\end{array}$ & $\boldsymbol{U}_{\boldsymbol{i}}\left(\boldsymbol{a}_{\boldsymbol{i}}\right)$ \\
\hline 1 & $\mathrm{~K} 1$ & 85 & 15 \\
\hline 2 & $\mathrm{~K} 2$ & 80 & 20 \\
\hline 3 & $\mathrm{~K} 3$ & 85 & 15 \\
\hline 4 & $\mathrm{~K} 4$ & 70 & 30 \\
\hline
\end{tabular}

5. Kemudian menghitung nilai keseluruhan utility

$$
U_{i}\left(a_{i}\right)=\sum_{j=1}^{m} W_{j} U_{i}(a i):
$$

Tabel 7. Nilai Keseluruhan Utility Apel Anna (C1)

\begin{tabular}{cccc}
\hline $\begin{array}{c}\text { Penilaian } \\
\text { Responden }\end{array}$ & $\boldsymbol{U}_{\boldsymbol{i}}\left(\boldsymbol{a}_{\boldsymbol{i}}\right)$ & $\boldsymbol{W j}$ & $\boldsymbol{U}_{\boldsymbol{i}}\left(\boldsymbol{a}_{\boldsymbol{i}}\right)$ \\
\hline $\mathrm{K} 1$ & 20 & 0.35 & 7 \\
\hline $\mathrm{K} 2$ & 10 & 0.30 & 3 \\
\hline $\mathrm{K} 3$ & 15 & 0.25 & 3.75 \\
\hline $\mathrm{K} 4$ & 15 & 0.1 & 1.5 \\
\hline $\begin{array}{c}\text { Total Nilai Utility } \\
\text { Keseluruhan dari HP1 }\end{array}$ & 15.25 \\
\hline
\end{tabular}


Available online at http://jurnal.stmikroyal.ac.id/index.php/jurteksi

Tabel 8. Nilai Keseluruhan Utility Apel Fuji (C2)

\begin{tabular}{cccc}
\hline $\begin{array}{c}\text { Penilaian } \\
\text { Responden }\end{array}$ & $\boldsymbol{U}_{\boldsymbol{i}}\left(\boldsymbol{a}_{\boldsymbol{i}}\right)$ & $\boldsymbol{W j}$ & $\boldsymbol{U}_{\boldsymbol{i}}\left(\boldsymbol{a}_{\boldsymbol{i}}\right)$ \\
\hline $\mathrm{K} 1$ & 20 & 0.35 & 7 \\
\hline $\mathrm{K} 2$ & 25 & 0.30 & 7.5 \\
\hline $\mathrm{K} 3$ & 10 & 0.25 & 2.5 \\
\hline $\mathrm{K} 4$ & 20 & 0.1 & 2 \\
\hline $\begin{array}{c}\text { Total Nilai Utility } \\
\text { Keseluruhan dari HP1 }\end{array}$ & 19 \\
\hline
\end{tabular}

Tabel 9. Nilai Keseluruhan Utility Apel Granny Smith (C3)

\begin{tabular}{cccc}
\hline $\begin{array}{c}\text { Penilaian } \\
\text { Responden }\end{array}$ & $\boldsymbol{U}_{\boldsymbol{i}}\left(\boldsymbol{a}_{\boldsymbol{i}}\right)$ & $\boldsymbol{W j}$ & $\boldsymbol{U}_{\boldsymbol{i}}\left(\boldsymbol{a}_{\boldsymbol{i}}\right)$ \\
\hline $\mathrm{K} 1$ & 15 & 0.35 & 5.25 \\
\hline $\mathrm{K} 2$ & 20 & 0.30 & 6 \\
\hline $\mathrm{K} 3$ & 15 & 0.25 & 3.75 \\
\hline $\mathrm{K} 4$ & 30 & 0.1 & 2 \\
\hline $\begin{array}{c}\text { Total Nilai Utility } \\
\text { Keseluruhan dari HP1 }\end{array}$ & 18 \\
\hline
\end{tabular}

6. Menetapkan Hasil/Kepuasan

Tabel 10. Nilai Keseluruhan Utility Apel Granny Smith (C3)

\begin{tabular}{lc}
\hline \multicolumn{1}{c}{ Nama Alternatif } & $\begin{array}{c}\text { Hasil } \\
\text { Akhir }\end{array}$ \\
\hline Apel Anna (C1) & 15.25 \\
\hline Apel Fuji (C2) & 19 \\
\hline Apel Granny Smith (C3) & 18 \\
\hline
\end{tabular}

\section{DAFTAR PUSTAKA}

Sanjaya, A., dkk. (2015). Rekomendasi Pembelian Grosi Pada Toko Mainan Menggunakan Metode SMART. Samarinda: Jurnal Metode SMART. I(1)

Ladjamudin, A. 2013. Analisis dan Desain Sistem Informasi. Yogyakarta: Graha Ilmu.
Dari tabel 10, maka dapat ditarik kesimpulan bahwasannya alternatif terbaik diperoleh ialah Apel Anna (C1) dengan nilai terakhir 15.25 (nilai $<16$ ) maka sebagai komoditi pengguna jasa yang dikatakan berkualitas untuk konsumsi masyarakat.

\section{SIMPULAN}

Dalam menganalisa permasalahan terhadap penentuan kualitas pemasukan pangan segar asal tumbuhan dapat dilakukan dengan Metode Smart. Metode Smart merupakan metode pengambilan keputusan multi atribut yang digunakan untuk mendukung keputusan dalam memilih antara beberapa alternatif suatu metode dalam sistem pendukung keputusan untuk melakukan perhitungan yang cukup akurat.

Merancang aplikasi sistem pendukung keputusan yang mengadopsi metode Smart dilakukan dengan beberapa kriteria yaitu lamanya hari pasca panen, kondisi fisik, warna, dan residu pestisida. Hasil aplikasinya berupa laporan atau hasil akhir penentuan kualitas pemasukan pangan segar asal tumbuhan. Penerapan metode Smart menghasilkan suatu perhitungan yang dapat dimanfaatkan untuk mengambil keputusan atau kebijakan dimasa yang akan datang.

Rosa, A.S. \& Shalahuddin, M. (2014). Rekayasa Perangkat lunak. Bandung: Informatika.

Widara, A.P. \& Winiarti, S. (2015). Sistem Pendukung Keputusan Dalam Penilaian Kineja Pegawai Untuk Kenaikan Jabatan Pegawai Menggunakan Metode GAP Kompetensi (Studi Kasus 
JURTEKSI (Jurnal Teknologi dan Sistem Informasi)

Vol. IV No. 1, Des 2017, hlm. 7 - 12

Available online at http://jurnal.stmikroyal.ac.id/index.php/jurteksi
ISSN 2407-1811 (print) ISSN 2550-0201 (online) \begin{tabular}{llr}
\hline \hline Perusahaan & Perkasa & Jaya \\
Compuretail). & Jurnal & Sarjana
\end{tabular}
TeknikInformatika. 1(2): 2338 5197. 
Jurnal Pena Edukasi

ISSN 2407-0769

Vol. 4 No. 2, Maret 2017

e-ISSN 2549-4694 